\title{
Evaluation of burden syndrome in caregivers of patients with dementias in a neurological hospital
}

\section{Abstract}

Objectives: Evaluate caregivers' burden degree of dementia patients and probable associated factors.

Method: It is an observational descriptive crosscut study conducted with 101 caregivers of patients treated in a specialized outpatient clinic. Socioeconomic questionnaire, Zarit Burden Interview (ZBI) and WHOQOL-Bref were used.

Results: Higher prevalence of mild (43.5\%) and moderate burden (36.6\%) were identified, but $84.1 \%$ of the caregivers had some degree of burden. Most of them had regular quality of life $(50.5 \%)$. Factors associated with increased burden were: older age of the caregiver ( $p=0,0622)$, longer weekly caring hours $(p=0,043)$, longer caring years $(p=0,001)$, primary caregiver $(p=0,009)$ and advanced stage of dementia $(p=0,0287)$. Also higher the burden, lower the caregiver's quality of life $(p=0,001)$.

Conclusion: Burden impact on caregivers' heath is underestimated. It would be pertinent to evaluate this syndrome with its risk factors during their appointments.

Keywords: dementia, alzheimer's disease, caregiver burden
Volume 2 Issue 6 - 2018

\author{
Ulisses Percegona Neto,' Alexandre \\ Pissette Di Remigio,' Alan Bueno,' Lucas \\ Luiz Marchese Campagnolo,' Veronice \\ Krause Martinez de Souza, ${ }^{2}$ Ricardo Krause \\ Martinez de Souza, ${ }^{2}$ Vitor Last Pintarelli,' \\ Eliane Mara Cesário Pereira Maluf' \\ 'Medical School, Universidade Positivo (UP), Brazil \\ ${ }^{2}$ Neurology Institute of Curitiba (Instituto de Neurologia de \\ Curitiba - INC), Brazil
}

Correspondence: Alexandre Pissette Di Remigio, Bruno
Filgueira Street, 93 ap. 161 80240-220 Curitiba, Paraná State,
Brazil,Tel 55(4I)98895-2833, Email alexandre.pdr@hotmail.com

Received: November 07, 2017 | Published: December 21, 2018

\section{Introduction}

Caregiver Burnout Syndrome features signs and symptoms which result from a burden feeling experienced by a caregiver when performing several potentially stress-generated tasks, along with its deleterious effects. ${ }^{1}$ Family caregivers of people suffering from dementia often describe such experience as "long-term stress and frustration". ${ }^{2}$ Among the factors associated with caregiver burnout, the most important are depression, functional and cognitive impairment. ${ }^{3}$ This syndrome mainly affects primary caregivers, and may result in their lives' disruption. ${ }^{4}$ That disruption, or burnout, has three fundamental aspects: emotional exhaustion, depersonalization and reduced personal accomplishment. The first aspect consists of lack of energy, enthusiasm and impotence to deal with their emotional resources. Depersonalization is conceptualized as an indifferent attitude towards the care recipient. The third aspect refers to the tendency of negative assessment of their activities. ${ }^{5}$

In a study by Engelhardt et al. ${ }^{6}$ it was found that " $60 \%$ of the caregivers may develop adverse physical and psychological symptoms". The most prevalent physical symptoms are: arterial hypertension, digestive disorders, respiratory diseases and infection susceptibility. The most incident psychological symptoms are: depression, anxiety and insomnia. ${ }^{6}$ The consequences for being a caregiver are: emotional burden, negative feelings, physical outcomes, financial, social and family changes. ${ }^{7}$ It is important to point out that those consequences may also affect non-family caregivers.

According to a metanalysis carried out by Adelman RD et al. ${ }^{8}$ $32 \%$ of the caregivers featured high burden, and $19 \%$ moderate burden, based on time spent with the patient and his/her degree of caregiving dependency. In the United States, in 2009, 43.5 million caregivers delivered care to people aged 50 years or over. ${ }^{8}$ According to data from the American Alzheimer's Association, almost $60 \%$ of caregivers to Alzheimer's sufferers rate their emotional stress as high or very high, and about $40 \%$ suffer from depression. ${ }^{9}$

Regarding patients with diagnosed dementia, it is possible to state that their families' dynamics will change in several aspects. In case of family caregivers, a relative may give up his (her) daily tasks to dedicate to that patient full time depending on the severity of the condition. ${ }^{10}$

The increase in the prevalence of dementias due to the process of demographic transition and the consequent increase in caregiver burnout syndrome justify the importance of carrying out studies on this syndrome.

\section{Methods}

It is an observational descriptive crosscut study held with caregivers of elderly patients diagnosed with dementia, treated at the outpatient clinic of the Instituto de Neurologia de Curitiba (INCNeurology Institute of Curitiba).

The sample was constituted by 101 caregivers, from both genders, whose data were collected from August, 2014 to July, 2015. As inclusion criteria, the following parameters were adopted: to be primary caregivers of patients diagnosed with dementia, and to comply with the informed consent term.

Data were collected by means of a socioeconomic questionnaire filled out by the participants, including: age, sex, schooling, income, number of caregivers, residence and length of caregiving hours. Zarit Burden Interview (ZBI), validated in Brazil, was also applied, with 22 questions assessing the impact of mental and physical diseases on caregivers. In addition, the World Health Organization Quality of Life (WHOQOL)-Bref questionnaire, developed by a group of the World Health Organization, also validated in Brazil, was applied, with 26 questions to measure caregivers' quality of life. The Clinical Dementia Rating (CDR) was applied by a neurologist in the same day of the questionnaire to assess care recipients' dementia stage.

The study was approved by the committee on ethics and research from the Instituto de Neurologia de Curitiba (Neurological Institute of Curitiba), Paraná State, Brazil, under N. 730.054. 


\section{Results}

\section{Caregivers' profile}

The sample entailed $86(85.15 \%)$ female caregivers and 15 $(14.85 \%)$ male caregivers, mean age of 53.67 years, standard deviation=15.23. Most of them were Caucasian $(88-87.13 \%), 55$ (54.46\%) had complete higher education, and 39 (38.61\%) belonged to social class C. Caregivers' sociodemographic profile is fully shown in the table below (Table 1). Social class A represents families with mensal income superior to 20 minimum wages, $\mathrm{B}$ represents families with mensal income between 10 and 20 minimum wages, $C$ represents families with mensal income between 4 and 10 minimum wages, D represents families with mensal income between 2 and 4 minimum wages and $\mathrm{E}$ represents families with mensal income till 1 minimum wage ( 880 real). ${ }^{11}$

Table I Caregivers' sociodemographic profile and caregivers' rating
According to the table below (Table 1), most of them were primary family caregivers (89-88.12\%), and $62(61,39 \%)$ were single caregivers. As for family relations, spouses and children were in equal number, entailing 42 (41,58\%) each. Mean caregiving time length was 107,30 weekly hours, standard deviation $=63.28$, and caregiving years of 3.27 years, standard deviation $=2.63$.

\section{Patients' profile}

Patients' profile was 48 (52.17\%) females and 44 (47.83\%) males, mean age of 74.49 years, standard deviation $(\mathrm{SD})=9.68$. The most prevalent diagnosis was Alzheimer dementia for 40 of them (43.48\%), mild CDR in 31 of them $(33.7 \%)$, moderate in $38(41.3 \%)$, and severe in $23(25.00 \%)$. Patients' sociodemographic profile is fully shown in the table below (Table 2). The difference in the number of caregivers and patients is due to the fact some patients have more than one caregiver.

\begin{tabular}{|c|c|c|c|c|c|}
\hline Caregivers' Total & 101 & & & & \\
\hline Sex & $\mathbf{N}$ & $\%$ & Schooling & $\mathbf{n}$ & $\%$ \\
\hline Male & 15 & 14.85 & No Studies & 1 & 0.99 \\
\hline Female & 86 & 85.15 & Incomplete Middle School & 6 & 5.94 \\
\hline \multirow[t]{4}{*}{ Age (years) } & Mean & $\Sigma$ & Complete Middle School & 10 & 9.9 \\
\hline & 53.67 & 15.23 & Incomplete High School & 2 & 1.98 \\
\hline & & & Complete High School & 24 & 23.76 \\
\hline & & & Incomplete Higher Education & 3 & 2.97 \\
\hline Social Class & $\mathbf{N}$ & $\%$ & Complete Higher Education & 55 & 54.46 \\
\hline A & 11 & 10.89 & Ethnicity & n & $\%$ \\
\hline B & 13 & 12.87 & Caucasian & 88 & 87.13 \\
\hline $\mathrm{C}$ & 39 & 38.61 & Mixed & 9 & 8.91 \\
\hline $\mathrm{D}$ & 14 & 13.86 & Black & 1 & 0.99 \\
\hline $\mathrm{E}$ & 14 & 13.86 & Asian & 3 & 2.97 \\
\hline Not reported & 10 & 9.9 & & & \\
\hline Caregiver Type & $\mathbf{n}$ & $\%$ & Family Relationship & $\mathrm{n}$ & $\%$ \\
\hline Family Primary & 89 & 88.12 & Spouse & 42 & 41.58 \\
\hline Professional & 6 & 5.94 & Child & 42 & 41.58 \\
\hline Primary & & & Other & 17 & 16.83 \\
\hline Family Secondary & 5 & 4.95 & & & \\
\hline \multirow[t]{2}{*}{ Professional Secondary } & 1 & 0.99 & & & \\
\hline & & & Weekly time length & Mean & SD \\
\hline Caregivers $\mathbf{N}$ & n & $\%$ & & 107.3 & 63.28 \\
\hline 1 & 62 & 61.39 & Caregiving time length & & \\
\hline 2 & 30 & 29.7 & (years) & Mean & SD \\
\hline 3 or more & 9 & 8.91 & & 3.27 & 2.63 \\
\hline
\end{tabular}




\section{Burden and quality of life}

From 101 interviewed caregivers, $85(84.16 \%)$ had a significant level of burden according to the ZBI (ZBI>21), ZBI mean of 37.08 (mild burden), $\mathrm{SD}=15.21$ (Table 3 ). If we consider burden degree, we had $15(14.85 \%)$ with little or no burden, $44(43.56 \%)$ with mild burden, $37(36.63 \%)$ with moderate burden, and $5(4.95 \%)$ with severe burden (Graph 1). The mean score of quality of life of 101 interviewed caregivers was 2.32 (poor quality of life), $\mathrm{SD}=0.79$. Among them, 3 (2.97) had poor quality of life $(1-2,9), 51(50.55 \%)$ had regular quality of life $(3-3,9), 45(44.55 \%)$ had good quality of life $(4-4,9)$, and 2 $(1.98 \%)$ had very good quality of life (5) (Table 3 )

Ordinal variables were evaluated by means of the Spearman correlation test, except for the number of caregivers who were evaluated by means of the Mann-Whitney Test. From the variables which evidenced some statistically significant burden correlation (Table 4), only quality of life presented high-moderate inverse correlation, that is, higher the burden, lower the quality of life $(\mathrm{p}=.0001)$. However, weekly caregiving time length $(\mathrm{p}=.043)$ and yearly caregiving time length $(\mathrm{p}=.0001)$ evidenced low-moderate direct correlations, which means that longer the time (weekly or yearly caregiving time length), worse the burden. Older caregiving age evidenced a trend to direct correlation of burden worsening $(\mathrm{p}=.0622)$, which means that burden has a tendency to be higher in older caregivers. Dementia staging $(\mathrm{CDR})(\mathrm{p}=.0287)$ evidenced low direct correlation, only single caregivers were considered in order to obtain a significant result. Schooling $(\mathrm{p}=.301)$, income $(\mathrm{p}=.4663)$, and number of caregivers (bilateral $\mathrm{p}=.3271$ ) did not evidence any statistical significance.

Mann-Whitney comparative test was used to nominal correlations, with statistically significant result only for caregivers' type (bilateral $\mathrm{p}=.009)$, evidencing that family primary caregivers suffer more than the other types (graph 1). Caregivers' sex evidenced only a trend (bilateral $\mathrm{p}=.1065$ ) that females suffer more than males (graph 3). Caregivers' family relationship did not show any statistical significance (bilateral $\mathrm{p}=.7452$ ), not detecting spouses' higher burden than children's.

Table 2 Patient's profile

\begin{tabular}{|c|c|c|c|c|c|}
\hline Patients total & 92 & & & & \\
\hline Sex & $\mathbf{N}$ & $\%$ & Diagnosis & n & $\%$ \\
\hline Male & 44 & 47.83 & Alzheimer & 40 & 43.48 \\
\hline \multirow[t]{2}{*}{ Female } & 48 & 52.17 & Vascular Dem & 8 & 8.7 \\
\hline & & & Mixed Dem & 15 & 16.3 \\
\hline \multirow[t]{3}{*}{ Age (years) } & Mean & SD & Lewy Body Dem & 5 & 5.43 \\
\hline & 74.49 & 9.68 & NPH & 5 & 5.43 \\
\hline & & & Non-specified Dem & 5 & 5.43 \\
\hline CDR & $\mathbf{N}$ & $\%$ & Other Dem & 14 & 15.22 \\
\hline Mild & 31 & 33.7 & & & \\
\hline Moderate & 38 & 41.3 & & & \\
\hline Severe & 23 & 25 & & & \\
\hline
\end{tabular}

Table 3 Burden degree and quality of life

\begin{tabular}{llllll}
\hline Burden & Mean & SD & Quality of life & Mean & SD \\
\hline ZBI & 37.08 & 15.21 & WHOQOL- Bref & 2.32 & 0.79 \\
& & & & $\mathbf{n}$ & $\%$ \\
\hline ZBI $>21$ & $\mathbf{N}$ & $\mathbf{\%}$ & & 3 & 2.97 \\
No or Little burden & 15 & $14.85 \%$ & Regular & 51 & 50.55 \\
Mild burden & 44 & $43.56 \%$ & Good & 45 & 44.55 \\
Moderate burden & 37 & $36.63 \%$ & Very good & 2 & 1.98 \\
Severe burden & 5 & $4.95 \%$ & & & \\
\hline
\end{tabular}


Table 4 Correlation table

\begin{tabular}{llll}
\hline & Correlation & Spearman Coeficient (rs) & p Value \\
\hline ZBI x WHOQOL bref & High/Moderate Inverse & -0.5641 & 0.001 \\
ZBI x caregiving weekly time length & Low/Moderate Direct & 0,28151 & 0.043 \\
ZBI x caregiving yearly time length & Low/Moderate Direct & 0,483 & 0.001 \\
ZBI xCaregiver's Age & Low/Moderate/Direct & 0.1862 & 0.0622 \\
ZBI x Caregiver's Schooling & No correlation & 0.1039 & 0.301 \\
ZBI x Caregiver's Social Class & No correlation & 0.0733 & 0.4663 \\
ZBI* x CDR** & Low Direct & 0.2278 & 0.0287 \\
\hline
\end{tabular}

*ZBI value to single caregivers

***atients' CDR to single caregivers

ZBI

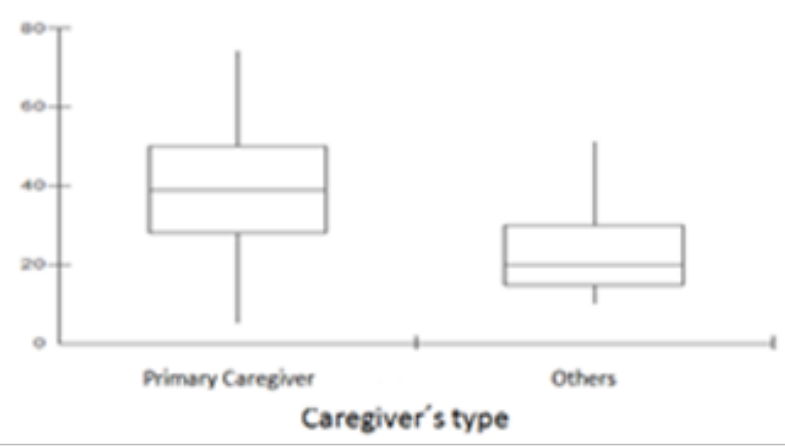

Graph I Burden X Caregiver's type.

\section{Discussion}

\section{Caregivers' profile}

Prevalence of females was found in the systematic review by Adelman et al. ${ }^{8}$ as well as in other Brazilian studies. ${ }^{1,5,12,13}$ That is probably explained by women's social role some decades ago, when they had very few activities apart from the household ones, being wife and older daughters the main responsible for the support network hierarchy. ${ }^{14}$ It is suggested that females have a higher risk correlation to caregiver overburden; the systematic review by Adelman et al. ${ }^{8}$ studies by Springate \& Tremont ${ }^{16}$ and Ivarone et al. ${ }^{15}$ found higher burden degree on female caregivers. ${ }^{5,8,15}$ It must be considered that women are the major caregivers, and males' lower frequency as caregivers is reflected in small samples in these studies, which may influence the results.

Mean age was high (53.6 years), associated with high weekly caregiving time length (107 hours/week) for several years (3.27 years), indicating that caring demands a long time, being this role taken by retired relatives, which evidences that many patients are cared by other elders. ${ }^{14,16}$ Caring for this kind of patients demands full time, thus high weekly time length ( 8 daily hours) is a common finding in Brazil. ${ }^{14,17}$

\section{Burden and quality of live}

Springate and Tremont in the USA found that age was a statistically significant predictor for overburden by means of the multiple regression method $(\mathrm{p}<0.01) .{ }^{16}$ However, many Brazilian studies did not find statistical significance in this correlation., $5,14,17,18$ In order to analyze this discrepancy in literature, it must be taken into account not only the difference in the populations, United States and Brazil, but also the difference in methodology. While Springate \& Tremont ${ }^{16}$ analyzed burden divided in three dimensions (direct impact on caregiver's life, guilt and frustration), Brazilian studies, in general, analyzed it as a whole, without subdividing it in dimensions. ${ }^{5,14,16-18}$ Burden would be likely to have direct correlation with the caregiver's age, due to the high demands of this kind of caring. However, this impact is more probably restricted to the physical aspects of caring than to the psychosocial ones.

There has been no agreement whether or not the high levels of caregiving time length are related to burden increase. Several Brazilian studies have not found statistical significance in that correlation. ${ }^{5,17,19}$ Such a difference may be related to the heterogeneous way that the studies approach that variable. In the mentioned study, it was used in absolute values of weekly caregiving time length in order to consider weekly caregiving time length for obtaining more reliable results. However, very varied categories to divide such time length were found in the literature. Some approach the daily time length, others divide it in a dichotomous way, while others in time length categories, and still others in more restricted time intervals.

Besides taking very long time length, mean caregiving years of 3.73.8 years were found. ${ }^{5,16}$ There has not been agreement on this theme, either, in such a way that several studies do not approach this variable. Some only register it, but its impact is not considered, while others did not find any types of association. ${ }^{17}$ In some Brazilian studies, such as Garrido \& Menezes ${ }^{17}$ and Silva et al. ${ }^{14}$ this direct correlation was presented: the longer caregiving time length, the worse is the burden. According to Garrido \& Menezes ${ }^{17}$ this finding can be explained by the "wear-out hypothesis", which means that years of exposition to caregiving stress would gradually wear out caregivers' physical and psychological potential to deal with caring demands, thus hindering their well-being.

Some discrepancies were found in relation to the profile. Unlike several Brazilian studies, where the oldest daughters account for the majority of caregivers, ${ }^{5,17,19}$ an even distribution among spouses and daughters may be a reflection of spouses' longevity in the studied population, enabling them to take this role more frequently. Another aspect found is higher education level $(54.46 \%$ with complete higher 
education) in relation to the average, while only $41 \%$ in Truzzi et al. ${ }^{5}$ and in Garrido \& Menezes ${ }^{17}$ only $20.4 \%$ of the caregivers have more than 8 years of schooling. ${ }^{5,17}$ That sample characteristic is due to the fact that the healthcare service is only provided to private or health insurance patients.

It was evidenced that primary family caregivers feature higher degree of suffering than other types of caregivers. According to Borghi et al. ${ }^{20}$ primary caregivers concentrate bigger responsibilities caring for patients, as well as they dedicate the greatest part of their time to this task, while the other types of caregivers mostly carry out complementary tasks.

Although most caregivers feature mild burden (44\%), which is according to several Brazilian findings evidencing mean mild burden, ${ }^{14,15,17,18}$ about $84.16 \%$ of the assessed caregivers have some degree of burden (ZBI>20), which accounts for some degree of wellbeing and health impairment, as well as the prevalence of that disease. Some studies also found similar values, such as Springate $\&$ Tremont ${ }^{16}$ $83.9 \%$ of 206 family caregivers of dementia patients suffered from burden. 16 Likewise, Loureio et al. ${ }^{18}$ evidenced burden prevalence of $84.6 \%$, among 52 caregivers.

About $50 \%$ of the studied caregivers with regular quality of life shows the high demand from the caring practice, not only physically but also emotionally, associated with the fact that caregivers very often hinder their lives in order to dedicate to caring for dementia patients. Several studies got to the same conclusion that those caregivers' assessment on their quality of life is negative. ${ }^{21-23}$

By analyzing burden and quality of life, it is evidenced a highmoderate inverse correlation, the higher the burden level (ZBI), the worse perception of the quality of life. ${ }^{23-26}$ In addition, by correlating caregiver burden variables and quality of life, the authors concluded that the lower the mean scoring of the general quality of life rate and other domains, the higher the ZBI mean scoring. Therefore, the higher the burden, the lower the quality of life scores. ${ }^{26}$

It is possible to infer that as dementia progression occurs and, consequently, dependency increases, so do caregivers' demands and their suffering. Similar results were found in Brazilian and international studies. For example, Kang et al. ${ }^{3}$ correlated staging with a higher level of caregiver burden. Springate \& Tremont ${ }^{16}$ found low correlation between the degree of dementia and burden. However, Truzzi et al. ${ }^{5}$ evidenced the correlation between staging and the emotional exhaustion of burden.

The study has some limitations as the sample only is able to represent the service of dementia of the INC hospital. Another factor that should be considered is the cultural concerns of the Brazilian families (women' social roles decades ago).

\section{Conclusion}

Caregivers, particularly the primary ones, are usually overlooked by health professionals in relation to their caregiving difficulties as well as their health, psychosocial problems, hindering their wellbeing and their patients'. It would be pertinent to assess burden risk factors such as sex, age, type of caregivers, caregiving time length, caregiving years and dementia staging, in addition to others, such as depression, anxiety and financial problems for early detection and intervention of the most susceptible to this syndrome.

\section{Acknowledgments}

None.

\section{Conflicts of interest}

The authors declare there is no conflict of interest.

\section{References}

1. http://www.scie 1 o.br/scie 1 o.php? pid=S 0104 $07072006000400006 \&$ script $=$ sci abstract\&tlng $=p$

2. Etters L, Goodall D, Harrison BE. Caregiver burden among dementia patient caregivers: a review of the literature. $J$ Am Acad Nurse Pract. 2008;20(8):423-428.

3. Kang HS, Myung W, Na DL, et al. Factors associated with caregiver burden in patients with Alzheimer's disease. Psychiatry Investig. 2014;11(2):152-159.

4. http://scielo.sld.cu/scielo.php?script=sci arttext\&pid=S0864-03192001000200007

5. Truzzi A, Valente L, Ulstein I, et al. Burnout in familial caregivers of patients with dementia. Braz J Psychiatry. 2012;34(4):405-412.

6. Engelhardt E, Dourado M, Lacks J. A Doença de Alzheimer e o impacto nos cuidadores. Revista Brasileira de Neurologia. 2005;14(2):5-11

7. Thomas P, Hazif-Thomas C, Pareault M. Sleep disturbances in home caregivers of persons with dementia. Encephale. 2010;36(2):159-165.

8. Adelman RD, Tmanova LL, Delgado D, et al. Caregiver burden: a clinical review. JAMA. 2014;311(10):1052-1060.

9. Alzheimer's Association. Alzheimer's Disease: Facts and Figures. 2015.

10. Papáleo Netto M. Tratado de Gerontologia. 2nd ed. São Paulo, Brazil: Editora Atheneu; 2007:125-126,302-305.

11. Faixas Salariais X Classe Social-Qual a sua classe social?. 2016.

12. $\mathrm{htt}$ : ///www.scielo.br/scielo.php?script=sci arttext\&pid=S0104-42302007000600015

13. Christofoletti G, Oliani MM, Bucken-Gobbi LT, et al. Physical activity attenuates neuropsychiatric disturbances and caregiver burden in patiens with dementia. Clinics (Sao Paulo). 2011;66(4):613-618.

14. ht t p://www.scielo.br/scielo.php? pid=S 1809 $98232012000400011 \&$ script $=$ sci abstract $\&$ tlng $=p t$

15. Ivarone A, Ziello AR, Pastore F, et al. Caregiver burden and coping strategies in caregivers of patients with Alzheimer's disease. Neuropsychiatr Dis Treat. 2014;10:1407-1413.

16. Springate BA, Tremont G. Dimensions of caregiver burden in dementia: impact of demographic, mood and care recipient variables. Am J Geriatr Psychiatry. 2014;22(3):294-300.

17. h t t p://www.scielo.br/scielo.php? pid=S 0034 $89102004000600012 \&$ script $=$ sci abstract\&tlng $=p t$

18. http://www.scielo.br/pdf/reeusp/v47n5/pt 0080-6234reeusp-47-05-1129.pdf

19. Santos RL, Sousa MFB, Simões-Neto JP, et al. Caregivers' quality of life in mild and moderate dementia. Arq Neuropsiquiatr. 2014;72(12):931937.

20. Borghi AC, Castro VC, Marcon SS, et al. Overload of families taking care of elderly people with Alzheimer's disease: a comparative study. Rev Lat Am Enfermagem. 2013;21(4):876-883.

21. http://www.scielo.br/pdf/jbpsiq/v57n4/a11v57n4.pdf 
22. Andrieu S, Rive B, Guilhaume C, et al. New assessment of dependency in demented patients: Impact on the quality of life in informal caregivers Psychiatry Clin Neurosci. 2007;61(3):234-242.

23. http://www.scielo.br/pdf/ape/v22n5/09.pdf

24. ht t p://www.s c i e lo.br/s c i e lo.ph p p id=S 1809 $98232011000300011 \&$ script $=$ sci_abstract\&tlng=pt
25. McPherson CJ, Wilson KG, Chyurlia L, et al. The caregiving relationship and quality of life among partners of stroke survivors: a cross-sectional study. Health Qual Life Outcomes. 2011;9:29.

26. ht t p://ww w.s cielo.br/s c i e lo.php? pid=S 0104 07072008000200007\&script $=$ sci_abstract\&tlng=pt 